\title{
Language games and scholarly writing
}

\author{
Rachel H. Ellaway ${ }^{1}$
}

Accepted: 2 September 2021

(c) The Author(s), under exclusive licence to Springer Nature B.V. 2021

\begin{abstract}
In this editorial the Editor considers the Wittgensteinian language games of scholarly writing in health professional education and their implications for creating and consuming the work that is published in this Journal and across the field in general.
\end{abstract}

Keywords Context $\cdot$ Language $\cdot$ Wittgenstein $\cdot$ Philosophy of science

I spent much of my last sabbatical thinking and writing about context, often in collaboration with my late colleague and friend Joanna Bates. One of the things that motivated our interest was trying to address the absence of contextual detail in much of the literature in our field. It seemed odd to us that context, if described at all, was typically covered in a sentence or so while methodological details went on for pages. That is not to say that methodological detail is excessive, only that context is often underreported. Given that context is so often a modifier (and at times even a confounder) in educational research and practice, the absence of information on the provenance and setting of research papers was troubling. After all, how transferable were these findings? Were there unmentioned dependencies or circumstances that might not apply elsewhere? How did context frame or constrain the questions asked, the methods used, the findings and interpretations proffered? Although we suggested ways in which context might be better addressed in scholarly works in our field, the problem persisted. It is still with us, in great part because of the elusive nature of language in describing contextual details in ways that are lean, comprehensive, and true to the scientific idiom in which the authors are writing.

I have just started another sabbatical, this time exploring concepts of pattern and augmentation, and I am yet again finding myself challenged by the linguistic articulation of these broad concepts. Depending on the discipline, paradigm of inquiry, or target audience, not only is there a fluidity and ambiguity in what terms mean and how they are used, there are troubling discontinuities and conflicts between them. Clearly, how we write matters. We communicate our own endeavours through the written word, and we consume the work of others through the words they write for us. We clearly need to be mindful and deliberate in our use of language. However, there sometimes seems to be less attention paid to how

Rachel H. Ellaway

rachel.ellaway@ucalgary.ca

1 Department of Community Health Sciences and Office of Health and Medical Education Scholarship, Cumming School of Medicine, University of Calgary, Calgary, AB, Canada 
we write than to what we write about. I am delighted to see a growing interest in improving writing as an academic skill, (Lingard \& Watling, 2021) but this is only a part of the story. We also need to consider how language changes according to context and to the language games that authors are playing, or at least to the language games they seem to be playing. In this editorial I will draw on Wittgenstein's concept of language games to reflect on issues in in scholarly writing. In doing so I will ask you as readers and potentially contributors to the Journal to reflect on the language games that you and others play, or feel obliged to play, in pursuit of scholarship in health professions education.

Rather than words, sentences, or other patterns of language having fixed or intrinsic meanings, Wittgenstein (1953) argued that the meaning of language changes according to the rules of the game being played. For 'game' we might also say idiom, context, or paradigm. As an example of this, the concept of significance changes according to whether it is being used in a statistical, hermeneutic, or critical theory context. It should come as no surprise in a field where many paradigms intersect that the language games of scientific and scholarly writing are quite varied and can be at times hard to navigate. A theoretical astronomer might struggle to make sense of the language games of autoethnography and vice versa. Even in this issue of Advances you will see some notable contrasts in the language games employed in the different papers we publish. In part these differences are reflected in the terminology used, indeed, when something is unfamiliar or seems to be deliberately obscure, we might instead refer to terminology as 'jargon'. Plavén-Sigray et al. (2017) noted "a growing use of general scientific jargon", which is "concerning for scientists and for the wider public, as they impact both the reproducibility and accessibility of research findings." The counterpoint for this is that all scientific writing has a necessary efficiency and flow, particularly when editors require parsimony and precision in the language they publish. If you have to define everything in order to make it accessible to any possible reader this efficiency is likely going to be substantially undermined.

Language games are not just a matter of definitions but also of axiological rhetoric, the values and ideologies that are advanced and contested in the language games we play. Let us take as an example the innocuous term 'normal'. Throughout the COVID19 pandemic everyone seemed to be considering the 'new normal' and now, as it begins to fade (or at least there is a strong will for it to fade), everyone seems be talking about a 'return to normal'. How do these two articulations of 'normal' compare? Do they mean that we are or should be restoring our pre-COVID practices, or is their intent more about regaining a sense of normality as a state of mind? Indeed, is 'normal' a proxy for 'what makes me happy', a sense of desired regularity, or something else altogether? Might 'normal' instead reflect a sense of means and modes that in turn reflect concepts of statistical distribution? Normal as a kind of distribution does not mean that non-normal is right or wrong, only that there are variations on how things might be distributed. However, 'normal' can also be used to define a right way of being compared to which everything else is wrong or invalid. Much of disability theory, decolonial, theory, and other forms of critical theory often focus on the way that concepts such as normal are used to exclude or coerce. Normal might even be considered to be a 'God Term' (Weaver, 1953), something intrinsically desirable and axiomatic, however it might be defined. One word, but a great many games that are or might be played with it.

Language games are also reflected in the different grammars and syntaxes of scientific writing. As an example, consider the use of voice. The physical and biological sciences have traditionally used a passive voice ('a study was conducted'), in part because it de-emphasizes the role of the researcher(s) and in part as a rhetorical to convey authority and gravitas. This grammar tends also to be used in communicating quantitative and 
experimental studies in the social sciences, which suggests that the language games are as much bound if not more to methodologies and philosophies of science than to foci of inquiry. By comparison, writing in the qualitative and hermeneutic sciences tends to use an active voice ('we conducted a study') reflecting the reflexivity and transparency these methodologies use to establish rigour. Those trained in the language games of sciences that use a passive voice often struggle with the language games of those that use the active voice, and vice versa. Nevertheless, it has been noted that there has been a shift in scientific writing from the passive to active voice over time (Banks, 2017). There are divided opinions as to why this has happened. For instance, Banks suggested that there is " a tendency for active verbs with first person pronoun subjects to occur in mental process rather than material process" (ibid) while Riley (1991) argued that "passive structures are more appropriate for expository purposes ... to describe procedures and present data ... active structures are more appropriate for argumentative purposes, in those sections where the author is criticizing previous research or advocating a new thesis."

The different language games we play, both within and across paradigms, might be expected to cause cognitive dissonance, and indeed they do, particularly for those ideologically committed to a particular paradigm to the exclusion or deprecation of others. If you or others you know get upset over the misuse of terms such as 'significant', 'theory', or 'hypothesis' you may be right (I am not saying these terms are never misused) but do pause and think whether what it is that is disagreeable, what language games are being played, and what the legitimacy of those games might be. Alternatively, you might like to consider the aesthetics of the language games that different authors play, for instance by considering the harmonies and dissonances they create through the language they use and the language they do not use. You might also consider the apparent rules of the language games people play. For instance, what is and is not permissible and legitimate (grammar), and what are the stylistic devices and variations authors employ to convey authority, significance, and generalizability in different kinds of language games?

You might also consider, as I often do, the problems that the use and abuse of language games can create for journals such as Advances. When editors and reviewers consider the 'raw' manuscripts we receive, we are often challenged by the ambiguities of terminology, by the disproportionate strengths or weaknesses of knowledge claims relative to the evidence to support them, or by failures and missteps in following the rules of the language game the authors are or should be playing. Not only should we ask what the authors' understanding of, say, competence was, but what its implications are for the language games used for presenting their review of the literature, articulating their methods, or reporting their results. This is a particular issue for field-based scholarship where paradigms can and often do intersect and potentially come into conflict. These conflicts may well be reflected in the logics of authors' use of language games. For instance, there are many logics associated with defining terms, including:

- Authors do not define their terms, apparently assuming they are self-evident.

- Authors use their own definition of their terms without apparently considering alternatives.

- Authors use someone else's definitions on an arbitrary basis, i.e., without justification or considering the implications.

- Authors consider alternative definitions but settle on someone else's definition, hopefully with some justification for doing so and some consideration of the consequences.

- Authors consider alternative definitions but still elect to use their own definitions, again with justifications and consideration of implications. 
- Authors situate their terms within a fluid discourse of different meanings and implications where the contrasts between definitions are more important than fixed definitions.

- Authors define brand-new terms, hopefully with some justification for their neologistic turns.

I will let readers draw their own conclusions about which of these strategies are more or less defensible in the different contexts of health professions education scholarship. However, I hope that they illustrate the language games that are present in even the most quotidian academic writing. I would ask you all therefore to be more mindful and deliberate in your appraisal of the language games we play and in their implications for the kinds of science we pursue and publish. More specifically, in Advances, which does not have a word count cap, I would ask you to appraise how the challenges of parsimony and efficiency are met (or not) and how they differ from those applicable in other journal contexts. I would also ask that, rather than this becoming a matter of policing or criticizing those who struggle with language games, that this be a generative aspect of scholarship where the mindful use of language games adds to the rigour and substance of the research we publish, and to its impact and uptake with whatever audiences it seeks to engage. You could start right here of course, by appraising the language games I have used (and maybe abused) in getting to this full stop.

\section{References}

Banks, D. (2017). The extent to which the passive voice is used in the scientific journal article, 1985-2015. Functional Linguistics, 4, 12. https://doi.org/10.1186/s40554-017-0045-5

Lingard, L., \& Watling, C. (2021). Story, not study: 30 brief lessons to inspire health researchers as writers. New York: Springer.

Plavén-Sigray, P., Matheson, G. J., Schiffler, B. C., \& Thompson, W. H. (2017). The readability of scientific texts is decreasing over time. eLife, 6, e27725. https://doi.org/10.7554/eLife.27725

Riley, K. (1991). Passive voice and rhetorical role in scientific writing. Journal of Technical Writing and Communication, 21(3), 239-257.

Weaver, R. M. (1953). The ethics of rhetoric. Davis: Hermagoras Press.

Wittgenstein, L. (1953). Philosophical investigations. New York: Wiley-Blackwell.

Publisher's Note Springer Nature remains neutral with regard to jurisdictional claims in published maps and institutional affiliations. 